\title{
Cancer researcher found guilty of negligence
}

\section{Quirin Schiermeier, Munich}

A university investigation has found the lead author of a contentious German cancer study guilty of gross negligence, but has cleared his 14 co-authors of misconduct.

The study, led by Alexander Kugler, formerly of the University of Göttingen, was published two years ago in Nature Medicine (A. Kugler et al. Nature Med. 6, 332-336; 2000). It claimed that kidney cancer could be treated using a vaccine made from tumour cells fused with healthy dendritic cells from the immune system.

But the university launched an investigation into the paper after allegations that Kugler and another co-author had included a picture downloaded from the Internet in another paper submitted for publication (see Nature 412, 8; 2001).

In a statement issued on 12 November, the University of Göttingen said that the Kugler paper "fails to meet the requirements of good scientific practice". It added that data in the study were handled incorrectly, and that information relevant in judging the vaccine's efficacy - such as whether the patients had received alternative treatments — was missing from the study.

Among other problems that were identified by the university's task force was the false claim that the vaccinations had been carried out under a clinical trial approved by an ethical committee. In fact, they were individual treatments which were later subsumed into a study for publication.

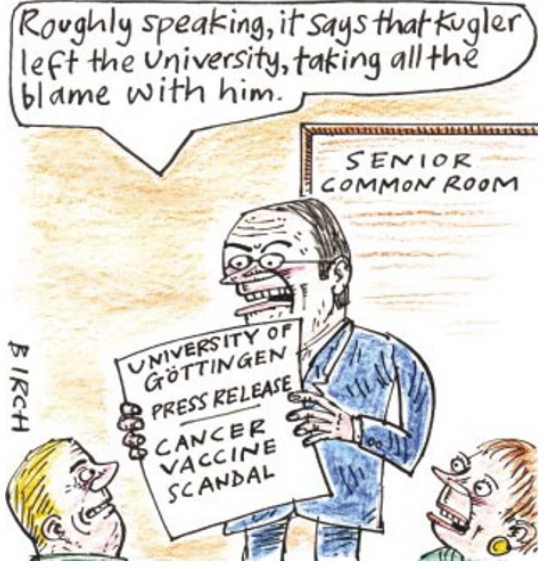

But the task force firmly apportions the blame to Kugler, who has since left research, and whose whereabouts is unknown. The 14 co-authors, including the heads of the university's institutes of urology and nephrology, Rolf-Hermann Ringert and Gerhard Müller, received only mild reprimands in the university's statement. The task force's full report has not been released publicly, pending comment from Kugler's co-authors, but the university says that a copy is being sent to Nature Medicine.

"I am taking this very seriously," says Beatrice Renault, editor of Nature Medicine, adding that she will need to read the report in full before deciding what course of action to take over the paper.
Despite doubts about the initial study, at least 400 patients have since been treated with the vaccine by Ringert and Müller. The results of these treatments have not been made public - but according to an unpublished analysis obtained by Nature, there were no significant tumour regressions among the 100 or so patients treated in Müller's department. Ringert, who has treated more than 300 patients, declines to comment on the vaccinations, saying that the results have not yet been fully analysed.

Ulrike Beisiegel, vice-dean for research and ombudswoman at the University of Hamburg, criticizes the slow release of information about the case. "It is urgent that all relevant information be revealed," she says. Beisiegel adds that the episode reflects deep-seated ethical problems in German clinical research.

Meanwhile, the DFG, Germany's main research funding agency, has announced its own investigation into the Kugler paper. Reinhard Grunwald, the agency's secretary general, says that it will seek to build on the university investigation and establish both the vaccine's therapeutic effects and the degree of responsibility borne by all of the authors of the paper.

The Göttingen research was supported by Fresenius, a biotechnology and healthcare company that is based in Bad Homburg, Germany, which is expected to obtain approval shortly for a fresh study of the vaccine's efficacy.

\section{Physics guidelines drop equal-responsibility clause}

\section{Geoff Brumfiel, Washington}

Responsibility for the integrity of a scientific paper need not always be carried by all the authors of the paper, according to ethical guidelines unveiled last week by the American Physical Society (APS).

The revised guidelines are the society's response to recent physics misconduct cases, including that of Jan Hendrik Schön, a researcher at Bell Laboratories in Murray Hill, New Jersey, who was found to have falsified data in several high-profile papers and was sacked in September (see Nature 419, 419-421; 2002). They contain an updated code of conduct and advice on how misconduct cases should be handled - but most significant is a revision of the duties of co-authors.

Previous APS guidelines stated that all authors held an equal share of responsibility for a paper. But several of Schön's co-authors were cleared of misconduct because they had simply supplied him with materials.
The new code states that all researchers share "some degree of responsibility" for papers that they co-author, but only some have responsibility for the entire paper. "These include, for example, co-authors who are accountable for the integrity of critical data reported in the paper, carry out the analysis, write the manuscript, present major findings at conferences, or provide scientific leadership," the guidelines say.

The move has the backing of many physicists, but also has critics, such as physicist David Goodstein, a vice-provost at the California Institute of Technology in Pasadena, who handles many of his institute's misconduct cases. Goodstein says that fraudulent data almost always find their way into print before senior researchers are alerted, so it is unfair to hold supervisors accountable. "The senior people are responsible for bringing suspicions to the attention of the proper authority, but they're not policemen," he says.
William Brinkman, president of the APS, says that he disagrees with Goodstein but is open to modifying the guidelines in the future. "These are not like Newton's laws they're not set in stone," says Brinkman. www.aps.org/statements

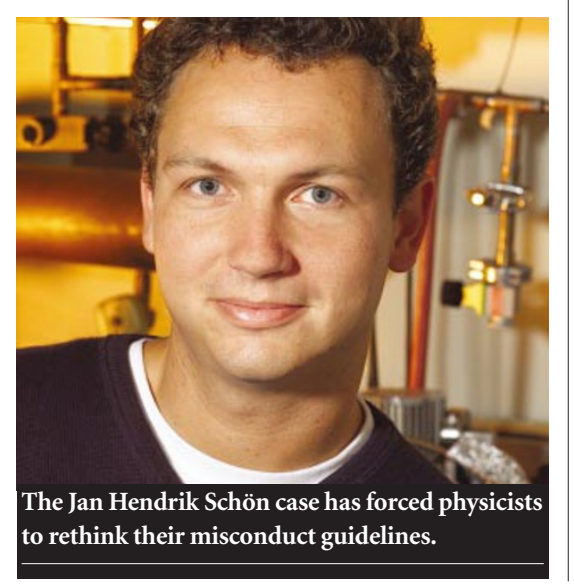

